\title{
Madrid: centro, periferia, subterráneo. Desmitificando una ciudad desde la mirada clandestina
}

\author{
Sanja Mihajlovik KostadinOVSKA \\ Universidad Complutense de Madrid \\ strabaraldasa@yahoo.com
}

Recibido: 14 de abril de 2011

Aceptado: 23 de mayo de 2011

\section{Resumen}

En este trabajo nos fijamos en determinados espacios de la ciudad de Madrid, vistos a través de tres novelas contemporáneas y sus protagonistas: unos inmigrantes ilegales. En estos espacios, primero mitificados y luego desmitificados, se (re)construye la compleja identidad de los que deciden emprender un viaje sin retorno.

Palabras clave: espacio, Madrid, desmitificación, migración, multiculturalidad.

Title: Madrid: center, periphery, underground. Demystification of a city from the clandestine point of view

\section{Abstract}

In this paper we observe some particular spaces of the city of Madrid reflected in three contemporary novels and from the point of view of their protagonists: the illegal immigrants. In these spaces, mythicized and then demystified, is where the complex identity of those who undertake a voyage without return is (re)constructed.

Keywords: space, Madrid, demystification, migration, multiculturality.

\section{Índice}

1. Introducción

2. Los novios búlgaros: se vende Europa del Este

3. El paseador de perros: recorriendo una periferia aletargada

4. El Metro: el mundo clandestino del subsuelo

5. Conclusiones

\section{Introducción}

El presente artículo, como del propio título se desprende, se propone ofrecer una mirada triádica del espacio de la ciudad de Madrid, vista a través de los protagonistas de tres novelas: Los novios búlgaros de Eduardo Mendicutti, El paseador de perros de Sergio Galarza y El Metro de Donato Ndongo. Hemos seleccionado estas tres novelas porque comparten la visión del emigrante desde la clandestinidad. Pero se trata de visiones fragmentadas, ya que en los tres textos hay espacios urbanos que, sea por el valor metafórico que adquieren, sea por la preferente ubicación de la acción novelística, prevalecen sobre 
otros; es decir, en el primer caso destacaremos el centro de Madrid, o más precisamente la Puerta del Sol y sus vecindades; en el segundo nos desplazaremos hacia la periferia madrileña, para descender en el tercer ejemplo hacia la "ciudad subterránea". Además, la selección de estas novelas nos permite testimoniar una ciudad multicultural en muchas "esferas" y "estratos", y representada por distintas comunidades extranjeras que conviven junto a los "autóctonos" también en el espacio real de la ciudad de Madrid: búlgaros o europeos del Este, latinoamericanos, africanos, etc.

Sin embargo, aunque creemos haber justificado nuestra elección, estando ante tres textos que hablan sobre el fenómeno migratorio y encontrándose dos de los tres autores en la situación de emigrado $^{1}$ (en el caso de Galarza) y exiliado ${ }^{2}$ (en el caso de Ndongo), consideramos oportuno detenernos sobre algunas puntualizaciones terminológicas.

La literatura de la migración, tal y como explica Nora $\mathrm{Moll}^{3}$, se refiere principalmente a la literatura escrita por migrantes (de primera, segunda o tercera generación), enunciada desde el país de acogida y en la lengua de la mayoría (la lengua del ex-colonizador en el caso de Inglaterra, Francia o España). Según esta definición y volviendo a nuestra selección, estaríamos ante dos novelas que sí entrarían en la llamada "literatura de la migración" -El paseador de perros y El Metro-, siendo el autor de la primera un peruano afincado en Madrid y el segundo, un ecuatoguineano que también reside en

\footnotetext{
${ }^{1}$ Preferimos utilizar aquí el vocablo emigrado que migrante, aunque el segundo sea más neutro, para destacar mediante el prefijo una situación que supone la salida del país natal y enlazarlo con la palabra exiliado con la que nos referimos al siguiente autor. De todas formas, es necesario apuntar que los motivos de Sergio Galarza de venir a Madrid, son más bien personales que económicos o políticos. Véase la entrevista concedida por Galarza a Radio IcatFM (Virgili 2010).

2 Donato Ndongo salió de su Guinea Ecuatorial natal en el ya lejano 1965 (cuando Guinea todavía era una colonia española) para terminar sus estudios en la metrópoli y, desde entonces, vive en España. Sin embargo, su anhelo de regresar a su tierra, obstaculizado por la situación política de su país tras lograr la independencia, lo convierte en un exiliado. Michael Ugarte (2010) en su libro Africans in Europe: The Culture of Exile and Emigration from Equatorial Guinea to Spain se refiere a esta particular situación de Ndongo con el neologismo "emixilio". 3 En "La letteratura della migrazione in Italia e in Europa: modelli a confronto", Moll (2008) incluye en este tipo de literatura a "autori migranti che vivono in Italia ed usano l'italiano como lingua d'espressione creativa e saggistica e sulle loro opere"; se usa "[i]l termine di letteratura inglese, oggi, solo ed exclusivamente in relazione alla residenza degli scrittori in Inghilterra, al di là della loro provenienza e delle loro radici etnico-culturali". En Introducción a la literatura comparada, la autora dice: "Muy pronto los mismos inmigrantes de primera generación pasan a formas narrativas y poéticas las más diversas, a elaboraciones literariamente complejas, usando con mayor agilidad la lengua del país de llegada (que las personas procedentes de las antiguas colonias donde ésta era lengua oficial ya poseían: piénsese en la India o el Magreb)" (Moll 2002: 383).
} 
España ${ }^{4}$; y la tercera novela, Los novios búlgaros, la clasificaríamos como una novela "sobre la inmigración" ${ }^{5}$. Sin dejar de notar la clara diferenciación que se hace mediante la prefijación ${ }^{6}$, es preciso apuntar también que si seguimos la biografía del escritor, habría que hacer otra vez la necesaria matización de que Ndongo es un exiliado y Galarza no, lo cual afecta inevitablemente a los textos en cuestión, y teniendo en cuenta el actual contexto político y sociocultural de los países de origen de estos dos autores, sería erróneo no situar El Metro dentro del discurso postcolonial, al que, sin embargo, no se adscribe El paseador de perros. En cuanto al aspecto lingüístico, y volviendo otra vez a la llamada literatura de la migración, estamos ante tres casos curiosos, si se tiene en cuenta que muchas veces la adopción de la lengua del ex colonizador o la lengua de la mayoría del país de acogida representa una especie de subversión. Aquí tenemos a un autor ecuatoguineano que utiliza el castellano sin pretender hacer una decisiva inversión desde el plano lingüístico (si exceptuamos el uso de algunos vocablos africanos que no vienen explicados como grombif o adjab); a un autor peruano, que deliberadamente se acerca al español peninsular (como consta en el epílogo del libro) y, curiosamente, entre las novelas elegidas para este artículo, la que más destaca por la "contaminación" lingüística de palabras búlgaras es la firmada por el autor español.

A pesar de esta variedad de enfoques y clasificaciones, creemos que aunque los autores de estas tres novelas son tanto nativos como extranjeros, aunque los textos están focalizados por diferentes tipos de narradores ${ }^{7}$ y los protagonistas provienen de latitudes distantes y distintas, observar los textos desde la óptica espacial nos permite

\footnotetext{
${ }^{4}$ Los dos autores utilizan la misma lengua como la mayoritariamente hablada en el país de acogida.

${ }^{5}$ Los novios búlgaros viene analizada en un relativamente reciente libro titulado $L a$ inmigración en la literatura española contemporánea (Andrés-Suárez, Kunz y D'Ors 2002), en el cual se hace referencia a textos que tratan la inmigración, es decir, no estamos ante la denominada literatura de la migración.

${ }^{6}$ En el extenso capítulo de Inés d'Ors "Léxico de la emigración" (2002: 21-108), se apunta ante todo a una disparidad tanto en la percepción como en la definición que los propios diccionarios ofrecen de los dos fenómenos. La autora subraya la falta de memoria histórica entre los españoles que, a pesar de su pasado reciente de país exportador de emigrantes, casi nunca perciben a los llegados a su país como emigrantes sino casi siempre como inmigrantes, con toda una serie de connotaciones negativas que este término conlleva. En el período de la "vieja ola" hacia América se hablaba de emigración y emigrantes tanto en la Península como en los países de destino. "En cambio, en la actualidad, casi nunca se alude a los extranjeros venidos a España como emigrantes: por lo general, se les designa como inmigrantes" (D'Ors 2002: 27).

${ }^{7}$ En el caso de Los novios búlgaros estamos ante un narrador testigo que no es el protagonista de la historia, sino que narra las peripecias del protagonista Kyril; en la novela El paseador de perros el narrador anónimo es un narrador protagonista; tratándose en el tercer ejemplo, El Metro, de un narrador omnisciente.
} 
establecer como punto en común el espacio convergente (la ciudad de Madrid) para poder desde allí trazar muchas relaciones e interrelaciones. Sin embargo, aunque la acción o parte de la acción novelística se sitúa en la ciudad de Madrid, no estamos en todos los casos ante unas novelas propiamente urbanas. Con la excepción de EI paseador de perros, donde el movimiento del protagonista está determinado por muchos lugares con claro referente en la ciudad real, en Los novios búlgaros el espacio que más destaca es el centro y La Puerta del Sol, pero la ciudad actúa más desde la ausencia, y en El Metro la ciudad se percibe casi exclusivamente desde sus profundidades -el metro- y se convierte en un espacio del anonimato ${ }^{8}$. De todas formas, como dice Dževad Karahasan, "en una narración la ciudad está siempre presente de manera inmanente" (Karahasan 2008: 160) ${ }^{9}$. Hablando de la historia del género narrativo relacionándolo con el crecimiento de las antiguas ciudades griegas, este autor apunta que una de las principales razones de la aparición de este género y a la vez su motivo dominante es el encuentro con el otro; la narración es "un discurso sobre el otro" (Karahasan 2008: 157). De manera similar, Roland Barthes en su texto Semiología y urbanismo habla de una dimensión erótica en el sentido más amplio y de la ciudad como "essentially and semantically [...] the place of our meeting with the other" (Barthes 1986: 96). Así nuestros textos, aunque -como hemos dicho- no todos pretenden ser historias urbanas, hablan de un único espacio ¿posible? donde se produce el encuentro con el nuevo y doblemente otro: el inmigrante.

Y para terminar esta introducción, y volviendo a la segunda parte de nuestro título, se nos impone una pregunta: ¿se transforma Madrid en una mítica ciudad literaria de la migración (clandestina)? La relativamente rápida transformación de la real ciudad de Madrid en un espacio multicultural transitado diariamente por miles de turistas y convertido ya en un nuevo hogar para numerosos inmigrantes de todas las nacionalidades, razas y estratos sociales, no pasa desapercibida para la literatura. Sin embargo, sería todavía temprano hablar de un importante corpus de obras ${ }^{10}$ que traten la migración extranjera hacia Madrid y que nos permitiera utilizar el mito moderno de esta ciudad como edén occidental. Tal y como para

\footnotetext{
${ }^{8}$ Estaríamos aquí ante un paradigmático "no lugar", término introducido por Marc Augé y definido como "espacio donde ni la identidad ni la relación ni la historia tienen verdadero sentido, donde la soledad se experimenta como exceso o vaciamiento de la individualidad" (Augé 1993: 92).

9 La traducción es nuestra.

${ }^{10}$ Mencionaremos aquí algunos títulos que tratan el tema de la inmigración hacia la ciudad de Madrid: Un día cuando pueda llevarte a Varsovia (1997) de Lorenzo Silva; la colección de relatos breves Lavapiés, microrrelatos (2001), en la que participan varios autores; Cosmofobia (2007) de Lucía Extebarria; y del venezolano Juan Carlos Méndez Guédez, Una tarde con campanas (2004).
} 
muchos inmigrantes reales Madrid es/era una puerta hacia Europa, en muchas de las novelas, y este es el caso de las que analizaremos aquí, los protagonistas eligen Madrid no como un destino final de su travesía migratoria, sino más bien por alguna casualidad. De todas formas, tanto como para los que terminan allí como para los que continúan su viaje, Madrid se revela para los protagonistas (y ahora estamos hablando solamente de los ficticios) como un bastión derrumbado del falso paraíso europeo; o, sirviéndonos de los términos de Greimas, la relación de estos personajes con la ciudad en el eje euforia-disforia se mueve desde una euforia principal hasta una aguda disforia (Greimas 1986: 34).

Los migrantes de estas tres novelas son, utilizando las palabras de la escritora Jarmila Očkayová (2006), como "Ulises invertidos". No añoran volver a la patria ${ }^{11}$, sino que miran hacia la meta que queda siempre más allá. Su viaje no es circular, sino como una "flecha" que "puede alcanzar o fallar el objetivo". En los ejemplos traídos aquí, Madrid es la ciudad de los desengaños y las flechas la traspasan abandonándola, pero no sin dejar huella.

\section{Los novios búlgaros: se vende Europa del Este}

Eduardo Mendicutti es uno de los primeros autores españoles ${ }^{12}$ que tratan el tema de la entonces todavía reciente y no tan masiva migración extranjera hacia la ciudad de Madrid. Los novios búlgaros es su novena novela y es la historia de Daniel Vergara y otras "locas" madrileñas, y sus encuentros o desencuentros con el "suculento enjambre" de los países del ex bloque socialista, representado por la inmigración búlgara, principalmente a través del personaje de Kyril. Todos los personajes búlgaros vienen a España en busca de una vida mejor, preparados para sacrificar hasta su "masculinidad" para poder saborear, aunque sea por un momento, los frutos del capitalismo, de un mundo rico y desarrollado. Aunque, como ya mencionamos, la novela no se propone ser una novela típicamente urbana, donde la ciudad adquiere un verdadero protagonismo, Madrid se hace visible y palpable gracias al constante desplazamiento de los nuevos "intrusos", los inmigrantes búlgaros. Venidos desde la "periferia"

\footnotetext{
${ }^{11}$ Este no sería el caso de la novela El Metro, como apuntaremos en la cuarta parte de este artículo, sin embargo, nos servimos de la metáfora utilizada por Jarmila Očkayová para constatar un viaje sin retorno del protagonista Obama Ondo, un viaje-flecha de un "Ulises invertido".

12 Marco Kunz (2002: 109-136) apunta que excluyendo Los espejismos de Gonzalo Hernández Guarch, escrito en 1972 (y publicado en 1998), que se podría considerar uno de los primeros textos sobre la inmigración ilegal, y la pieza teatral La mirada del hombre oscuro, de 1992, de Ignacio del Moral, Los novios búlgaros es una de las primeras novelas que tiene como tema la inmigración y muy probablemente la primera que trata la inmigración del Este de Europa.
} 
europea, deseosos de convertirse de la noche a la mañana en los nuevos parvenus, vemos a estos personajes "ocupando" el mismísimo centro de la ciudad -la Puerta del Sol-y, desde allí, moviéndose por todos lados en busca de las soluciones más variadas para obtener el dichoso permiso de estancia, su nueva identidad. La elección de esta plaza no es nada casual. Es la puerta que supuestamente lleva a la tierra prometida, es el kilómetro cero donde dejar el pasado atrás y empezar una nueva vida mejor. En el espacio público de esta plaza es donde se concentran estos "frescos" inmigrantes, que tras el derrumbamiento del Muro de Berlín abandonan sus patrias esperando encontrar su rincón en la "jungla capitalista"; los homosexuales españoles que están dispuestos a "ayudar" a estos pobres y desprotegidos en la "adaptación" a los nuevos patrones del mundo occidental, y los misioneros mormones, que también ven a esta inmigración como víctima necesitada de urgente "salvación". La Puerta del Sol se convierte así en una caldera que se llena constantemente de las ilusiones de todo inmigrante que pretende comprarse una felicidad instantánea borrando los vínculos con su tierra e intentando rehacer su identidad con el brillo del oro o los coches de lujo. Es precisamente el centro de la ciudad por donde el protagonista Kyril pasa para lucirse con el robado y "flamante" porsche, o donde ve en una joyería de la Gran Vía la gruesa cadena de oro que se convertirá en el símbolo del éxito que nunca alcanzará.

Al principio vemos a Kyril moviéndose con cierta desenvoltura por la zona céntrica:

Contestaba con monosílabos a las loquiansiosas que se le insinuaban en la Puerta del Sol; escuchaba en silencio, con una mirada de sorna, las pláticas dulzonas que los esquemáticos misioneros mormones distribuían en la Puerta del Sol entre los inmigrantes ociosos; pedía cigarrillos en los estancos, refrescos en las cafeterías, bolas en los billares, cabina de locutorio de la Telefónica de la Gran Vía, o el precio desmedido de unas botas vaqueras de piel de serpiente, con palabras escuetas y en un tono siempre algo insolente. (Mendicutti 1993: 25)

Es curioso notar en este párrafo que el uso de "monosílabos", "silencio", "palabras escuetas" es un anuncio de la comunicación interferida entre Kyril y los habitantes de la ciudad o, si se prefiere, entre Kyril y la ciudad. Una vez "abandonado" el lugar de las ilusiones - la Puerta del Sol y el centro-, Madrid se convierte para Kyril en un lugar borroso, inseguro, hasta hostil: duerme en los coches ajenos forzando la cerradura; se involucra en varios trabajos ilegales para después encontrar únicamente trabajos "nocturnos"; la recorre a gran velocidad sin realmente percibirla en su moto regalada, con la 
que más tarde tiene un accidente; o la observa desde la mirada mediatizada por una cámara que sólo capta un lujo lejano.

El desengaño de Kyril se hace más patente en el episodio del peep show. "Humillado, arrepentido, incapaz de hacerse rico con su cuerpo" (Mendicutti 1993: 122) vuelve de ese "viaje lleno de peligros" a casa de Daniel, que parece ser el único hombre con el que mantiene una cierta comunicación (aunque muchas veces se resume en el sexo mercenario), siendo esa amarga experiencia del peep show la máxima expresión de la explotación y de la incomunicación entre los hombres, separados por un vidrio, como si la miseria fuese contagiosa.

Después del viaje a Bulgaria y de la experiencia en la cárcel, vemos a Kyril resignado, trabajando de portero en varias discotecas madrileñas, sin el brío inicial que le hacía creer que podía dominar (¿domar?) la ciudad hostil como si fuera su moto -"un animal de musculatura metálica y zancada cilíndrica, arrogante, poderosa" (Mendicutti 1993: 102)-, pero de vidrio, hormigón, calles, plazas. EI viaje de Kyril a Madrid termina en una sala de pignoración hacia el Monte de Piedad, lejos de la céntrica Gran Vía y la joyería de sus ilusiones, donde pretendía dejar todo el oro con el que quería revestir su viejo yo, y se dirige con su mujer Kalina hacia una ciudad incierta de la periferia española.

En esta novela, Mendicutti no se sirve de la inmigración para hacer arte de la miseria ajena, una actitud que con gran ironía critica a través del personaje de Mogambo, que después de aprovecharse de los búlgaros, decide abstenerse de esos devaneos y se dedica a hacer dibujos titulados "Ladronzuelo búlgaro desnudo se lava las manos para purificarse tras un pequeño robo en un bulevar de París", o "Joven emigrante del Este de Europa espera a la intemperie la llegada de un ángel protector" (Mendicutti 1993: 117).

Mendicutti tampoco tiene la intención de presentar a los migrantes búlgaros como delincuentes -que sería la percepción que los medios de comunicación transmiten- sino que, a través de la elección de un narrador homodiegético que está dentro del relato pero cuenta la historia de otro, constata que Daniel (como la mayoría de los españoles), en realidad, recibe las informaciones sobre su amante (los inmigrantes) muchas veces de manera restringida 0 diferida:

Cierto que de otras hazañas ajenas a la legalidad emprendidas por Kyril -el cumplimiento del encargo de las lagartas holandesas, las manualidades clandestinas por cuenta del italiano, el secuestro del coche de Alex [...]- yo ni siquiera he sido testigo, todo lo conocí por referencias brumosas o indicios volubles. (Mendicutti 1993: 185) 
Madrid y su Puerta del Sol se perciben en esta novela como lugares deshumanizados, como un supermercado donde se trafica con los hombres, donde todo tiene un precio, sobre todo la dignidad humana. Y también se transforman en símbolo de tantas vidas desgastadas en busca de una vida mejor, de un falso paraíso terrenal:

El Este de Europa ya había dado de sí todo lo que podía. Ya había proporcionado satisfacción a sus sitiadores, consuelo y razón a los desertores, abundante material a los ladrones de niños, científico a precio de ganga, mano de obra especializada y baratísima, unos cuantos escritores atolondrados, futbolistas de talento a precio de ocasión, dolorosa alegría a los demócratas de buena voluntad y cuerpos jóvenes y necesitados a las agencias de servicio doméstico, a los puticlubs de carretera y a las pirañas concentradas en la Puerta del Sol. (Mendicutti 1993: 218)

\section{El paseador de perros: recorriendo una periferia aletargada}

El paseador de perros, publicada en 2009, es la primera novela del joven autor peruano Sergio Galarza, por la que obtuvo el reconocimiento "Nuevo talento de FNAC 2009". El texto, de trasfondo autobiográfico, ya que el propio autor como su protagonista es un migrante y también ejerció el oficio de paseador de perros, revela cómo muchos apuntan una "cara de Madrid que los turistas no suelen visitar" (Paz Soldán 2010) o que "no se ve en las postales turísticas" (Editorial Candaya 2009), es decir, una verdadera "crónica periférica de la capital española" (Guerra Bravo 2009). Aunque la novela no se centra únicamente en la periferia madrileña (el protagonista se mueve también por los barrios de La Latina y Malasaña, donde vive), conocemos más en profundidad barrios como Pozuelo, Coslada y la Moraleja porque de allí son principalmente los clientes de la agencia que ofrece el servicio de paseadores de perros, trabajo ejercido, como el mismo protagonista, prácticamente solo por inmigrantes. El "peregrinaje por la ruta incierta de los anhelos" (Galarza 2009: 7) que emprendió el anónimo narrador-protagonista, de una manera similar a la novela anterior, pronto viene sazonado no solo por la incertidumbre, sino también por el desengaño, la soledad, la incomunicación con los nativos.

Junto con su novia Laura Song, el protagonista decide irse de Lima, una ciudad gris, alejada del mundo europeo del "espectáculo", e instalarse en Madrid, una ciudad-puerto desde donde empezar una vida de viajero despreocupado hacia otros destinos europeos. Huyendo de la "falta de aire" de Lima y de un mundo con el que no se identificaba, truncando los lazos familiares, pronto la pareja topa con una ciudad hostil que "respiraba el polvo de las construcciones y el 
humo de la perpetua fiesta" (Galarza 2009: 10). Laura no consigue encontrar trabajo y siente que no "se ubica" en Madrid, así la vida del narrador tras la ruptura con Laura se limita prácticamente al trabajo solitario de paseador: "calor, soledad y bolsas negras para recoger mierda" (Galarza 2009: 44). Pero es justamente gracias a este oficio, al desplazamiento en varios medios de transporte y al recorrido a pie, como el narrador nos permite adentrarnos en el mundo de la periferia madrileña:

Pozuelo: "una zona de gente adinerada, con casas [...] alejadas del ruido y rodeadas de jardines enormes donde las podadoras de césped parecen coche deportivos" (Galarza 2009: 13); Alcorcón:

Sus calles con basura desparramada al lado de los contenedores, los parques con más latas y botellas rotas que flores, la gente vestida con ropa que parece donada por la Cruz Roja de Europa del Este, los jóvenes y sus coches explotando música sin cuerdas, viejos vegetando en las bancas y esquinas como espantapájaros, los rumanos y sus zapatos de escama, las rumanas y sus joyas de fantasía, los españoles que uno confunde con los rumanos, los latinos peleando por dinero desde los locutorios con alguien al otro lado del Atlántico, los bloques de edificios con sus balcones blancos de barandillas de metal, esas prisiones del extrarradio que recordaban el Cono Norte de Lima y a su imperio pacharaco. Cada vez que visitaba Alcorcón me sentía deportado del paraíso del Centro y me preguntaba de qué se reía esa gente viviendo en un lugar así. (Galarza 2009: 19);

\section{Coslada:}

Coslada, otro pueblo lejano convertido en ciudad, igual de deprimente que Alcorcón, un imperio de edificios de ladrillo, con parques de tierra regados de mierda y jóvenes mascando gritos mientras exhibían sus cadenas y pulseras de fantasía. [...] Coslada era, como la mayoría de pueblos de la periferia madrileña, la versión española de aquellos suburbios estadounidenses donde los jóvenes se matan por exceso de aburrimiento y fantasía. (Galarza 2009: 39-40)

Estas tres citas aportadas aquí nos permiten tener la visión del narrador de estos barrios del área metropolitana madrileña, diferentes y distantes del centro, unas pequeñas ciudades dentro de la gran metrópoli que no destacan por nada especial salvo por su suciedad, por la pobreza de los inmigrantes de una parte y los ricos "amurallados" por otra, junto a una juventud ociosa y sin valores. EI narrador no se identifica con esta ciudad de ladrillo, aunque tampoco lo vemos plenamente integrado en la zona céntrica de Malasaña donde vive, es decir, no se encuentra identificado ni con la antes anunciada ciudad "de la fiesta perpetua", que se limita a observar desde su balcón. 
Dejando atrás su pasado, la familia a la que raramente llama, la ciudad de Lima que en un punto confiesa que le ofrecía protección y seguridad al lado de su novia, el protagonista se convierte en un tipo huraño, que busca deliberadamente huir de la gente estando con sus mascotas. Sin embargo, gracias al trabajo de paseador se transforma también en un mudo testigo de la vida de los dueños de los animales. Conoce las debilidades enmascaradas detrás del lujo, las manías, la soledad y el abandono de la gente "relegada" a la periferia de una ciudad que vive y late al margen de ellos. Vaciado de la propia memoria, el protagonista se alimenta de los recuerdos de esta gente, quizá como una manera de llenar el hueco del desarraigo y buscar algún consuelo para su nunca soñada vida de inmigrante:

Cuando te dan las llaves de una casa entras en un matorral de recuerdos, en un cementerio donde la fuerza del olvido trata de destruir las lápidas que puedan llevarte por rutas de abismos, porque el pasado es un agujero negro. Ahí están el padre que mantiene a un mapache como único recuerdo de su hijo, el hombre que agoniza sin una pierna, la divorciada que alimenta su biblioteca de autoayuda cada semana con nuevos títulos, las abuelas que me preguntan si volveré al día siguiente, los pisos con la cama desecha y los platos sucios en el fregadero. (Galarza 2009: 43)

Viajar hacia la periferia madrileña en metro o en autobús le permite al narrador conocer una cara de la ciudad que probablemente no esperaba ver al salir de su país natal: una ciudad "invadida" por los inmigrantes. Sin dejar de notar un lenguaje poco políticamente correcto, incluso racista a veces, que representa a los inmigrantes como pobres, de mal gusto y de poca cultura, creemos que la intención del autor no es tanto criticar el fenómeno de la migración masiva, de la que él mismo es partícipe, sino evitar idealizar la figura del inmigrante y desmitificar la visión del occidente europeo como tierra de posibilidades. Además, como repite en varias ocasiones, los inmigrantes le sirven para situarse en algún "bando". Aunque no se distingue físicamente ni por la lengua de los nativos, siempre queda un rasgo que lo hace distinto: es la $X$ de su documento, una $X$ de extranjero que comparte con los demás inmigrantes:

Si la X no fuera la primera letra de mi documento de identidad, nadie me reconocería como inmigrante porque no uso zapatos con escamas ni ropa de imitación y mi cabello sólo brilla cuando no lo lavo en varios días. X de extranjero, X porque estás marcado. (Galarza 2009: 50)

Este pasaje nos confirma la visión de un ciudadano del mundo que aboga por la libertad de movimiento y critica la noción de una identidad únicamente comprobable a través de un documento. 
Como ya mencionamos, el protagonista acepta el trabajo de paseador por la simple razón de que, además de ganar dinero para sobrevivir, le permite estar lejos de la gente y sus problemas, pero esto al final le resulta imposible. Sin embargo, en el trato cotidiano con perros, gatos y otras mascotas, entre ellos un mapache, no encuentra un sustituto de la falta de relación con los humanos. Los perros que pasea son ajenos a sus problemas; no adquieren prácticamente ningún protagonismo, son la mera excusa del narrador para hablar de su situación de inmigrante que está lejos de realizar sus sueños, atado diariamente y sin descanso a un animal que actúa guiado solo por sus instintos. Sin embargo, mención aparte merece el mapache, al que se hace alusión ya desde las primeras líneas de la novela. La presencia de "ese mamífero gris plata que lleva un antifaz negro" (Galarza 2009: 7) en el texto adquiere unos valores metafóricos. La vida del animal enjaulado, hostil, solo y abandonado, que vive en la lujosa casa del anciano, se asemeja mucho a la del protagonista: solitario, huraño, obligado a moverse por la enorme ciudad como en una jaula, siguiendo unas rutas determinadas por su empleador JKF y las peticiones de los clientes. El antifaz "natural" del mapache es el antifaz que el protagonista debe llevar al trabajar como paseador, la única manera que le permite sobrevivir en un mundo que idealizaba desde Lima, creyendo que le ofrecería la posibilidad de asistir despreocupado a los innumerables conciertos de sus bandas favoritas. En un pasaje, el narrador se pregunta: "¿Cuántos días llevaba en la jaula? ¿Quién y dónde lo habría capturado? ¿Cuál era su edad? ¿Le gustaba viajar? ¿Qué lugares había conocido? ¿Tenía una familia esperándolo?" (Galarza 2009: 109).

Y aquí es donde otra vez podemos individuar una identificación del protagonista con el mapache anónimo, sin pasado, con sus anhelos y su libertad truncados. La huida del mapache de la jaula también coincide con el propósito del narrador de abandonar Madrid e ir a Francia, hacia un futuro incierto, pero huyendo también de la jaula madrileña, de su periferia estéril, de la alienación de sus dueños y del propio fracaso.

\section{El Metro: el mundo clandestino del subsuelo}

Donato Ndongo-Bidyogo es uno de los autores más importantes de Guinea Ecuatorial y aunque, con interrupciones, lleva viviendo en España desde 1965, la mirada en sus textos tanto ficcionales como críticos o ensayísticos se vuelve constantemente hacia su tierra. El Metro, sin embargo, no se sitúa en su natal Guinea, sino que cuenta la salida de un joven camerunés, Lambert Obama Ondo, de su pueblo de la región de Mbalmayo y su viaje hasta Europa. De manera similar a la reflexión que hace el protagonista en la novela: "el africano tenía 
que dejar de ser víctima para convertirse en héroe de su propia vida" (Ndongo-Bidyogo 2007: 433), Donato elige a este hombre común africano como héroe de una historia que pretende salvar del anonimato las travesías personales de tantos inmigrantes que arriban en pateras a las orillas de España.

Como Chad Montuori (2010) indica en su reseña de esta novela, la intención de Ndongo no es representar el fenómeno de la migración condicionado simplemente por razones económicas, y destaca que: "Donato Ndongo-Bidyogo refuses to accept the myopic assertion that the migratory journey is a single movement in space and a single movement in time". Por eso nos hace testigos del fatigoso periplo del protagonista, primero por varios países de África hasta su llegada al "edén" occidental, y que otra vez, como en las novelas anteriores, se revela como mero destino casual y provisional. Aunque la mayor parte de la novela se ubica en África, y el viaje por Madrid que analizaremos aquí se reduce prácticamente al primer capítulo, parte del capítulo XVII y el último, esta novela nos ofrece una valiosa mirada de la "ciudad subterránea", o sea, el Metro, que, anunciado ya desde el mismo título, adquiere un verdadero significado simbólico.

A diferencia de las novelas anteriormente analizadas, el apego de Lambert Obama Ondo a su tierra y la evocación de su pasado son perpetuos durante su viaje, y la construcción de la nueva identidad del migrante se hace posible a través de la constante pugna entre el aquí y allí, lo cual no era tan evidente en los otros dos textos. Obama Ondo se siente a la vez orgulloso de su "africanidad", pero no deja de sentirse inferior a los blancos, que en realidad es la asunción de esa percepción del otro. $Y$ de ahí viene también el discurso siempre dúplice cuando se refiere al Metro, el único lugar que viene a conocer en profundidad, dado que allí trabaja como vendedor ambulante: "cada vez que bajaba hacia el Metro: le parecía que se había transformado en un ser extraño, medio animal y medio humano, un gigantesco grombif que cada anochecida buscara su madriguera bajo los túneles de la ciudad" (Ndongo-Bidyogo 2007: 13).

El Metro es a la vez el gran prodigio del mundo occidental y "una madriguera", unos túneles luminosos y un mundo oscuro, animalesco y mítico, una ciudad bajo tierra, separada y alejada del mundo de arriba que se incrusta en la piel del personaje como en un ciborg. El Metro es unas veces un lugar temible -"le asaltaba como un comienzo de desazón cada vez que bajaba las escaleras mecánicas hacia las entrañas de la tierra" (Ndongo-Bidyogo 2007: 13)-, un lugar que engulle si no dominas bien sus reglas de comportamiento y funcionamiento, y otras veces, un refugio: "en cuanto oteaba a lo lejos la presencia de cualquier agente, recogía en pocos segundos su manta con la mercancía, echaba el hatillo a la espalda y se adentraba en el Metro" (Ndongo-Bidyogo 2007: 449). 
El mundo del Metro, que al conocerlo por primera vez le provoca "estupor, pasmo y fascinación" (Ndongo-Bidyogo 2007: 375), es un mundo donde también descubre la indiferencia de la gente ensimismada en sus problemas. Es un espacio donde aprende qué significa sentirse solo en medio de una multitud.

El autor a veces ironiza hablando del Metro como de una "escuela de comportamiento social" para el pobre "negrito" que hay que "civilizar", aunque sus métodos son también salvajes:

Porque ya lo decía el viejo Otuk Ekoro: en determinadas situaciones conviene ser un poco salvaje. Claro que resulta muy complicado vivir en la civilización, pues requiere una extraordinaria capacidad de adaptación, el mimetismo de un camaleón, además de ingenio, vigor, audacia y un aprendizaje continuo: armarse de valor y empujar con fuerza y sin miramientos los otros cuerpos para no quedar atrapado entre el tren y el bordillo [...]. (Ndongo-Bidyogo 2007: 381)

Aquí no podemos reproducir la cita entera que se extiende a más de una página, pero es interesante notar que el Metro en realidad es para Obama Ondo el único sitio donde le está permitido conocer al otro, observándolo detenidamente, haciéndose con una imagen global a partir de las pequeñeces de la gente, de sus ridículas manías, cambios de humor, hábitos, defectos. Es a través de este escudriñar en lo más humano como el protagonista llega hasta a identificarse con este espacio; un espacio donde no se sentirá perseguido por la policía o engañado por los empleadores sin escrúpulos, un lugar donde estar e intentar ser, vendiendo "esos escasos productos que consistían su negocio y todo su mundo" (Ndongo-Bidyogo 2007: 19). Allí es donde también "empezó a distinguir ciertos rostros de la multitud" (Ndongo-Bidyogo 2007: 450), a acostumbrarse, a hacer hasta amistades con los otros viajeros, y donde conoció a Lucía, una blanca con la que una noche sale. El encuentro con Lucía, que parece anunciar una reconciliación entre la rigidez de sus tradiciones y la modernidad, abogar por un mundo en el que se borren las diferencias raciales y el mestizaje sea una realidad asumida con normalidad, es irónicamente la principal causa del trágico final de Obama Ondo, que termina apuñalado por una banda de neonazis. Los temores expresados por el protagonista al principio de la novela -morir como un anónimo en un país extrañoparecen revelarse ciertos, ya que Obama Ondo muere solo, en un andén desierto, alcanzando a oír antes de expirar solamente los aullidos del tren, distante y ajeno a su tragedia. Sin embargo, este mecánico mundo subterráneo al final de la novela se convierte en el lugar místico y transcendental de las almas, donde paradójicamente ocurre el reencuentro con sus ancestros. 
Para terminar nuestro análisis de esta última novela querríamos destacar que, a pesar de la importancia del espacio del Metro, a lo largo de la novela se hacen breves menciones también a otros espacios de la ciudad de Madrid: como el aeropuerto de Barajas, su primer encuentro con el brillante mundo occidental; las calles luminosas e infinitas percibidas desde un coche; el parque del Retiro, donde se hace patente la incomunicación con los nativos que observa como en una "estampa", felices, despreocupados remando en el estanque. En el pasaje que reproducimos abajo, Obama Ondo es un ser desconectado del presente del país donde se encuentra viviendo como un emigrante: el estanque para él no es el ahora del descanso y de la paz, sino una reminiscencia de una infancia feliz o de una peligrosa travesía en la patera por el mar:

\begin{abstract}
Mientras el tiempo fue bueno, Obama Ondo colocaba la manta en el Retiro, bajo un árbol en el borde del estanque, $\mathrm{y}$, como los otros vendedores callejeros dispuestos en derredor, pasaba la jornada contemplando a la gente que circulaba por el parque, sobre todo a los niños que jugaban o a las jóvenes parejas que remaban en el lago. Esas estampas bucólicas le traían recuerdos de su pueblos, cuando, con alguno de sus amigos o en compañía de sus primos, subía a los cayucos para pescar [...]. Pero, [...] a veces asaltaban su mente escenas de su tenebroso periplo, y entonces la apacible superficie de la represa se convertía en mar bravío [...]. (Ndongo-Bidyogo 2007: 443-444)
\end{abstract}

\title{
5. Conclusiones
}

A través de estas tres novelas hemos visto cómo, desde los años 90 (Los novios búlgaros) hasta años más recientes (El Metro), la literatura testimonia la paulatina transformación de Madrid en una ciudad multicultural. Lo que tienen en común estos tres textos, cuyos autores son de nacionalidades distintas, es el desengaño de sus protagonistas con el "edén" occidental, del que acaban huyendo o que resulta ser una experiencia fatal. Estos protagonistas perciben la ciudad como un espacio hostil, asfixiante, humillante. La construcción de su nueva identidad viene determinada por el movimiento por la ciudad y llevada a cabo siempre a través del contacto, o mejor dicho, la falta de contacto con el otro. Los espacios que destacan en cada una de las tres novelas reciben un valor metafórico puestos en relación con sus habitantes "novatos": el centro se transforma en el lugar de las ilusiones y del fracaso; la periferia es un mundo variopinto que atrapa y enjaula; el metro, una ciudad en constante movimiento donde se agudizan la soledad, el abandono y la incomunicación.

En un sentido más amplio, el espacio de la ciudad de Madrid se podría considerar una heterotopía, tal y como la explica Michel 
Foucault (1998-2011). Madrid funciona como una especie de espejo para los migrantes, un lugar entre la utopía y la heterotopía, un lugar que existe en la realidad, en el que ellos se buscan a sí mismos e intentan reflejarse, pero desde su posición de clandestinidad lo único real es su ausencia ${ }^{13}$. Aunque según la definición de Foucault, los lugares públicos no son heterotopías -ya que para acceder a éstas son necesarias ciertas "normas"-, en nuestros tres textos se podrían encontrar ciertas correspondencias con este tipo de contraemplazamientos. Así, por ejemplo, el centro de Madrid en Los novios búlgaros comparte algunas características con las "heterotopías de crisis", ya que la pérdida de la "masculinidad" tiene lugar justamente en este espacio. La periferia de El paseador de perros se parece a una "heterotopía de la desviación", ya que el protagonista-inmigrante está, de alguna manera, obligado a ejercer el trabajo de paseador, como si la migración fuese una especie de desviación, y dada esa involuntaria "infracción" se ve relegado a la jaula periférica. En el tercer texto, El Metro, el mundo subterráneo se podría considerar un espacio que, a pesar de que el protagonista se sitúe en una única estación, conecta y remite a toda la ciudad (lo que correspondería al tercer principio de la heterotopía, siempre según Foucault) y es un también un espacio que permite sincronías o "heterocronías" (cuarto principio). Es decir, dentro del mundo moderno de la premura y de lo artificial, vemos a un inmigrante africano vendiendo artesanías provenientes de algún lugar y tiempo distantes.

En las tres novelas elegidas aquí, creemos que el espacio de Madrid no se percibe solamente desde los binomios centro / periferia, ciudad bajo tierra / ciudad sobre la tierra, sino que a través de la elección de los protagonistas inmigrantes se introduce un tercer espacio -vasto y desconocido, lejano y cercano a la vez. Es el mundo de donde provienen los migrantes y que constituye una circunferencia indefinida, más que una sempiterna periferia, alrededor de un punto -Madrid, un centro descentralizado. Ese mundo los protagonistas lo llevan consigo en sus travesías, y permanece imborrable a pesar de sus intentos de dejarlo atrás para siempre y reconstruir su nueva identidad en el nuevo mundo.

Madrid les hace un hueco a estos protagonistas, pero les reserva las butacas más alejadas. Les permite asistir al espectáculo, pero ya se han apagado las luces y hay que moverse a tientas y con cuidado, si uno quiere acercarse al escenario y comprobar desde cerca que las pelucas son de verdad pelucas.

\footnotetext{
13 "In the mirror, I see myself there where I am not, in an unreal, virtual space that opens behind the surface; I am over there, there where I am not, a sort of shadow that gives my own visibility to myself, that enables me to see myself there where I am absent $[\ldots]^{\prime \prime}$. (Foucault 1998-2011)
} 


\section{Bibliografía}

ANDRÉS-SUÁREZ, Irene; KUNZ, Marco; y D'ORS, Inés (2002): La inmigración en la literatura española contemporánea. Madrid: Verbum.

AUGÉ, Marc (1993): Los "no lugares". Espacios del anonimato. Una antropología de la sobremodernidad. Barcelona: Gedisa.

BARTHES, Roland (1986): "Semiology and the Urban", en M. Gottdiener y A. Ph. Lagopoulos (eds.), The city and the sign, pp. 87-98. New York: Columbia University Press.

EDITORIAL CANDAYA (2009): "Sergio Galarza, Paseador de perros" [en línea], en Candaya. En: http://www.candaya.com/paseadordeperros.htm [Consulta: 16/03/11].

FOUCAULT, Michel (1998-2011): "Of Other Spaces (1967), Heterotropias" [en línea]. Foucault.info. http://foucault.info/documents/heteroTopia/foucault. heteroTopia.en.h tml [Consulta: 08/05/2011].

GALARZA, Sergio (2009): El paseador de perros. Barcelona: Candaya.

GREIMAS, A. J. (1986): "For a Topological Semiotics", en M. Gottdiener y A. Ph. Lagopoulos (eds.), The city and the sign, pp. 25-54. New York: Columbia University Press.

GUERRA BRAVO, Cristián (2009): "Todos los perros de Galarza" [en línea]. Espacio Candaya, 9 de diciembre de 2009. En: http://espaciocandaya.wordpress.com/2009/12/09/todos-los-perrosde-galarza/ [Consulta: 20/03/11].

KARAHASAN, Dževad (2008): "Pripovijedati grad", en Visković Velimir (ed.), Sarajevske sveske, núm. 21/22, pp. 156-178.

KUNZ, Marco (2002): "La inmigración en la literatura española contemporánea: un panorama crític", en Irene Andrés-Suárez, Marco Kunz e Inés D'Ors, La inmigración en la literatura española contemporánea, pp. 109-136. Madrid: Verbum.

MENDICUTTI, Eduardo (2007): Los novios búlgaros. Barcelona: Tusquets.

MOLL, Nora (2002): "Imágenes del 'otro'. La literatura y los estudios interculturales", en Armando Gnisci (ed.), Introducción a la literatura comparada, pp. 347-389. Barcelona: Crítica.

MOLL, Nora (2008): "La letteratura della migrazione in Italia e in Europa: modelli a confronto" [en línea], en Armando Gnisci (ed.), Kúmá, Creolizzare I'Europa, núm. 15, giugno 2008. En: http:// www.disp.let.uniroma1.it/kuma/critica/kuma15moll2.pdf [Consulta: $16 / 03 / 11]$.

MONTUORI, Chad (2010): "Review: El Metro" [en línea]. Mester, 38 (1). Los Angeles: Department of Spanish and Portuguese, UC Los Angeles. En:

http://escholarship.org/uc/item/3tr5v9g8; jsessionid=A10571FF45A30 DCBF31FA4D5431D3518\#page-1 [Consulta: 01/04/11].

NDONGO-BIDYOGO, Donato (2007): El Metro. Barcelona: Cobre Ediciones.

OČKAYOVÁ, Jamila (2006): "Dalle parole di nostalgia alla nostalgia di parole" [en línea], en Armando Gnisci (ed.), Kúmá, Creolizzare l'Europa, núm. 12, ottobre $2006 . \quad$ En: 
http://www.disp.let/uniroma1.it/kuma/critica/kuma12nostalgia.html [Consulta: 16/03/11].

PAZ SOLDÁN, Edmundo (2010): "Sergio Galarza, paseador de perros" [en línea]. El Boomeran $(g)$. Blog literario en español, 3 de febrero de 2010. En: http://www.elboomeran.com/blogpost/117/8483/edmundo-paz-soldan/sergio-galarza-paseador-deperros/ [Consulta: 20/03/11].

SALVO, Jorge A. (2003): "La formación de identidad en novela hispano africana 1950-1990" [en línea], tesis doctoral, en Literatura de Guinea Ecuatorial. Florida: Florida State University. Disponible en Cervantes virtual: http://descargas.cervantesvirtual.com/servlet/SirveObras/568184021 02381663554679/013525.pdf [Consulta: 01/04/11].

UGARTE, Michael (2010): Africans in Europe: The Culture of Exile and Emigration from Equatorial Guinea to Spain. Illinois: Board of Trustees of the University of Illinois. Versión incompleta disponible en Google books: http://books.google.com/books?id=rJoxnTZzBCUC\&printsec=frontcov er\&dq=Africans+in+Europe: + The+Culture+of+Exile+and+Emigration + from+Equatorial+Guinea+to+Spain\&source=bl\&ots=El sRIDye2\&sig =B2bNdU95zNWsZyKew8EOB4TsZSw\&hl=en\&ei= c6mTfPFKcbtsgazp

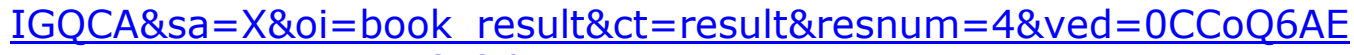
wAw\#v=onepage\&q\&f=false

VIRGILI, Montse (2010): "Conversación con Sergio Galarza", en Cabaret Elèctric. Radio IcatFM, 13 de enero de 2010. En: http://www.candaya.com/paseadoricatfm.mp3 [Consulta: 20/03/11]. 